\title{
Tiempo mesiánico y narración \\ Para una interpretación teológica de las prácticas narrativas de las víctimas
}

\author{
CARLOS MENDOZA-ÁLVAREZ \\ Departamento de Ciencias Religiosas \\ Universidad Iberoamericana Ciudad de México \\ carlos.mendoza@ibero.mx \\ (D)https://orcid.org/0000-0002-0614-3091
}

Resumen: Este artículo plantea elementos para el debate interdisciplinario sobre la idea teológica de tiempo mesiánico, que fue secularizada por la filosofía política moderna del siglo XX desvirtuando e invisibilizando el sentido de la temporalidad kairológica. Ésta en tanto contracción del tiempo mesiánico y anticipación kairológica, así como la vivencia originaria de la redención humano-divina posible en el corazón de la historia gracias a los actos de donación de las personas justas. Retomando ideas clave de pensadores occidentales críticos a la modernidad ilustrada en su vertiente secularizante, se proponen elementos para una teología del tiempo mesiánico, en sentido posmoderno y descolonial, como claves hermenéuticas para comprender las vivencias, prácticas simbólicas y narrativas de personas y comunidades de sobrevivientes de la violencia sistémica, en medio de la crisis civilizatoria en curso, quienes subvierten la violencia por medio de actos de memoria, justicia y amor de donación.

Palabras clave: Tiempo mesiánico, tiempo kairológico, sobrevivientes.

Abstract: This article proposes elements for an interdisciplinary debate on the theological idea of messianic time secularized by modern political philosophy of the 20th century and how it distorts and erases the sense of kairological temporality as a contraction of messianic time and kairological anticipation. We also discuss how the acts of donation of just persons enable the original experience of human-divine redemption in the heart of history. By taking key ideas of western thinkers critical of enlightened modernity in its secularizing aspect, we propose elements for a theology of the messianic time in a postmodern and decolonial sense. These elements serve as hermeneutic keys to understand the experiences, symbolic practices and narratives of peoples and communities who are survivors of systemic violence amid the current civilizational crisis, who subvert violence through acts of memory, justice, and selfless love.

Keywords: messianic time, kairological time, survivors. 
Tradikim yachinu shechinah ba-aret:

Los justos preparan la chekinah en la tierra ${ }^{1}$.

\section{INTRODUCCIÓN ${ }^{2}$}

Contar historias de vida es un acto de memoria personal y colectiva que nos permite afirmar nuestras subjetividades en el presente, habitando una temporalidad propia en la que, o bien nos inventamos en cada época como humanidad abierta a la esperanza o, inexorablemente, quedamos atrapados en interminables círculos de fatalidad, propios de un futuro que nunca llega.

En este ámbito de la memoria colectiva, es importante recordar que la modernidad instrumental impuso su narrativa de futuro con la concomitante idea de progreso. Un tiempo nunca alcanzado, según la advertencia de Iván Illich $^{3}$ hace ya varias décadas, apenas entrevisto como un espejismo del sujeto emancipado por medio de la tecnología, pero atrapado en su propia aventura egoica que con el paso del tiempo se ha tornado devastación y caos planetario.

Sin embargo, existe otra posibilidad de contar la historia, realizada siempre de manera discreta y como acto de resistencia: la historia desde los vencidos, como señaló Walter Benjamin. Memoria que suele ser despreciada por los poderes políticos y de facto en turno. En ese sentido, podemos tejer de manera colectiva una teología de la historia desde las víctimas. Se tratará de una narrativa contrahegemónica que surge desde sus resistencias y espiritualidades diversas.

En el fondo, se propone recuperar una memoria a partir de narrativas abiertas a la esperanza, conscientes del presente conflictivo y del pasado traumático -transformado por la resiliencia- que se ha heredado tras la violencia fratricida y sororicida, pero sin claudicar ante ella. Una rememoración que nos da la posibilidad de reconectarnos con el entorno de una casa común devastada y en proceso de sanación: el cuerpo social herido de la humanidad, unido al cuerpo de la hermana tierra que también es violentada por la codicia

${ }^{1}$ Una cita de Gershom Scholem en su diario de noviembre de 1916 (Tagebücher, nebst Aufsätzen und Entwürfen bis 1923, 419), en Peter D. FENVES. The Messianic reduction: Walter Benjamin and the Shape of Time (Stanford University Press, Stanford 2011) 216. En cuanto a la expresión "los justos de las naciones" son diversas las menciones en el Talmud. La más conocida es aquella sobre los Tradikim Nestarim (Sanhedrin 97b, Sukkah 45b), los 36 justos de las naciones que, por su vida justa, mantienen viva a la humanidad de cara a la gloria divina. En línea: https://www.sefaria.org/Sanhedrin.97b?lang=bi (consulta: 17/09/2020).

2 Este artículo forma parte del Proyecto interdisciplinar de investigación "Narrativas de resistencia 2020-2022", inscrito en la División de Investigación y Posgrado de la Universidad Iberoamericana Ciudad de México. Es un adelanto del argumento que será desarrollado en el segundo volumen de la trilogía sobre la idea de tradición, en su vertiente de narración desde los sobrevivientes, como expresión del tiempo mesiánico.

3 I. ILLICH, Los ríos al norte del futuro. Conversaciones con David Cayley (Alios Ventos, México 2020). 
de una civilización humana en decadencia. Se busca así contar las historias de un cuerpo intersubjetivo que habitamos por medio de la palabra y de las acciones simbólicas, tejiendo significados en una red de relatos de sentido que cobijan nuestro paso por el mundo en medio del sinsentido.

Cabe mencionar, además, que los actos de rememoración -contados en primera persona por las propias víctimas- acontecen siempre en medio de una historia que es lugar de conflicto de interpretaciones, cada una de ellas expresando un mundo de la vida singular, sea el del perpetrador o el de la víctima, de la clase hegemónica o de los subalternos, del macho dominante o de las mujeres y las demás subjetividades negadas en su diversidad de género, de la supremacía blanca o de los pueblos de color.

El siglo XX fue escenario de una revuelta cultural contra la historia escrita por los dominadores. El filósofo español Reyes Mate, siguiendo a Walter Benjamin, describe, en los siguientes términos, la opción de aquella otra escritura de la historia realizada desde la negatividad:

La desigualdad entre los hombres es un hecho histórico, algo que se produce en el tiempo y por la voluntad de los humanos: ¿pueden los herederos de injusticias pasadas desentenderse de la culpabilidad de sus antepasados? No pueden, por más que haya que hablar en su caso de responsabilidad hacia los "otros desiguales" y no de culpabilidad (que es personal e intransferible). No se puede renunciar a la universalidad, pero tampoco se la puede entender positivamente, tal y como querían las filosofías de la historia. ¿Por qué no pensar en una universalidad negativa? Esa es la pista que sigue Walter Benjamin, aunque no la siga hasta el final ${ }^{4}$.

Contar historias desde el reverso de la historia oficial implicará, por tanto, participar de manera activa en una disputa del espacio público en pos de la elaboración de una memoria colectiva, casi siempre controlada por los poderes en turno, pero ahora resignificada como actos de resistencia anamnética. Por eso, cuando esas narrativas son contadas por personas y colectivos invisibilizados por el poder hegemónico -sea económico, cultural, religioso, patriarcal, político o de mafias criminales- adquieren entonces el tono de un clamor (po)ético ${ }^{5}$ con una potencia inusitada y de una subversión política de diversos alcances, como prácticas de resignificación cultural y espiritual del mundo dado.

\footnotetext{
${ }^{4}$ Reyes MATE (ed.), Filosofía de la historia (Editorial Trotta, Madrid 2005) 17.

5 Tal es la perspectiva literaria desarrollada en Barcelona por Noemí Acedo en torno a la memoria feminista. Véase N. ACEDO-Alonso, "Moradas del ser. Notas sobre arte y testimonio en el pensamiento de Hannah Arendt y la escritura de Nora Strejilevich", América Latina Hoy 78 (2018), en línea: https://revistas.usal.es/index.php/11302887/article/view/alh2018787386 (consulta: 27/08/2020).
} 
En este ambiente creado por las resistencias culturales y espirituales en América Latina en décadas recientes -marcadas por las autonomías políticas, culturales, epistémicas y espirituales- se propone una interpretación del fondo teologal de esa construcción de una historia desde la negatividad como destello de redención, es decir, como anticipación kairológica de la vida plena humanodivina.

\section{DE LA INSUFICIENCIA DEL TIEMPO LINEAL NIETZSCHEANO}

Como parte de una genealogía de la filosofía de la historia moderna, Reyes Mate describe de manera acertada -ubicado en tiempos de plena crisis de la modernidad- la noción hegeliana de la historia como progreso, sustituida por el eterno retorno como idea ligada al superhombre de Nietzsche, en estos términos:

Cabe preguntarse entonces por esa manera de pensar en la que la historia es sustituida por el "eterno retorno", el sujeto es declarado mera ficción, se toma al lenguaje por pura metáfora y se hace del Superhombre una inteligencia sin historia, sin pathos y sin moral: ¿no estaremos sustituyendo la razón por el mito?, ¿no es el Superhombre una imitación del hombre?, ¿no habrá que buscar a la razón por el lado de la "apocalíptica"?, ¿no habrá que relacionar emancipación, felicidad, solidaridad con aquella cultura que sólo sabe pensar la subjetividad desde la intersubjetividad? 6

Hay que recordar que el superhombre nietzscheano representaba un contrapunto al Angelus novus de Benjamin. La figura de la historia del eterno retorno se oponía a la redención mesiánica, leída en clave del pasado que ha sido negado pero que, por la memoria, puede ser redimido por actos revolucionarios:

Nietzsche tiene razón al derivar toda su filosofía de la muerte de Dios, esto es, de la liquidación del pensar judeocristiano. Se equivoca, sin embargo, al emparentar la concepción teleológica del tiempo con la del pensamiento judeocristiano. La Apocalíptica judeocristiana se cifra en el concepto de "interrupción” y no en el teleológico. Eso es lo que se opone frontalmente a su eterno retorno. Y no parece difícil -contra Nietzsche- relacionar la eternidad del retorno con la concepción lineal del tiempo: en ambos, el imperio de la fuerza anónima del tiempo sobre los sujetos; en ambos, la incesante necesidad de progresar o crear sobre las espaldas de lo dado, y ¿qué es el progreso -genio y figura del tiempo evolutivo- sino la expresión eminente, tal y como la vio el Angelus Novus, de la dialéctica destrucción/construcción??

${ }^{6}$ Reyes MATE (ed.), Filosofía de la bistoria, 286.

${ }^{7}$ Reyes Mate (ed.), Filosofía de la historia, 285. 
Para buscar una fuente alterna que haga posible repensar la filosofía de la historia, el pensador español apela a la noción benjaminiana del tiempo mesiánico, como solución al enigma de una filosofía de la historia desde aquella perspectiva del progreso y de los vencedores que dominó la concepción hegeliana de la historia guiada por el Espíritu absoluto. En efecto, desde una perspectiva marxista con trasfondo judío, Benjamin apelaba al pasado posible que surge de aquellos sujetos que han sido aniquilados por los poderes hegemónicos ${ }^{8}$.

Ciertamente, debemos a Benjamin la conciencia moderna de los derechos de los muertos y del papel crucial de la memoria para construir el presente como una reivindicación de los vencidos. Pero, en su crítica a Nietzsche, Reyes Mate se queda en la exterioridad de la temporalidad kairológica porque ha asumido sin más la secularización benjaminiana de hacer de la experiencia particular de un pueblo de esclavos un principio universal, pero sin ahondar en el sentido antropológico y escatológico de la temporalidad mesiánica que le devolvería su carácter universal concreto. Así explica su opción hermenéutica:

La espera en algo por-venir, eso es lo que define el concepto de escatología con el que ahora se viste el tiempo. La plenitud o consumación de los tiempos está en ese futuro anunciado. Ahora bien, esa novedad salvadora que está por venir y cuya venida acaba con el tiempo no hay que entenderla como si se tratara del final del tiempo lineal. No es el telos de la concepción lineal. Puestos en esa tesitura habría que decir que el tiempo apocalíptico es intrahistórico. La consumación mesiánica del tiempo sería poner fin a la lógica de los tiempos que corren porque su curso es catastrófico y de seguir así nos llevaría a la catástrofe; pero esa quiebra del continum se produce dentro del tiempo cronológico 9 .

En este contexto, nosotros postulamos aquí la urgencia de recuperar un sentido teológico -en clave posmoderna y descolonial- del tiempo mesiánico. Consiste en afirmar que las narrativas de las víctimas sistémicas que salen de la zona del no-ser tienen la capacidad de devenir una anticipación mesiánica de la memoria del cuerpo herido de la humanidad que espera con dolores de parto (véase Romanos 8,22) el alumbramiento de un mundo nuevo. Acontecimiento que aquí evocamos como redención en tanto existencia kairológica, que hace posible la religación de lo humano y creatural con lo divino. En efecto, ese mundo que surge de la subversión de lo hegemónico tiene la potencia de experiencia y la

\footnotetext{
8 “A Benjamin le interesa el pasado posible, el que aún no ha tenido lugar pero que es posible si el presente se deja asaltar por esa parte inédita del pasado que pugna por hacer valer sus derechos; lo importante es, pues, el presente, pero no un presente visto como la última etapa de una historia que se reconstruye desde la ciencia, sino que se construye desde la memoria" (Reyes MATE [ed.], Filosofía de la historia, 275).

${ }^{9}$ Reyes Mate (ed.), Filosofía de la historia, 283.
} 
imaginación histórica necesarias para superar la línea abismal de la exclusión, abriendo así posibilidades sociales, éticas y espirituales de edificación de un mundo alterno, distinto al que predomina con las sucesivas idolatrías del poder, del dinero y de las violencias de diversa índole que aquejan a la humanidad desde el primer asesinato, fundador de la cultura, como señaló René Girard ${ }^{10}$.

Con este trasfondo, se propone en los siguientes apartados algunos elementos filosóficos y teológicos para pensar las prácticas narrativas como actos de resistencia politica y espiritual, por los cuales las víctimas de la violencia sistémica del mundo contemporáneo abren intersticios de sentido en medio del sinsentido que genera el pensamiento abismal de nuestro tiempo -marcado por el patriarcado heteronormativo, el capitalismo voraz, el colonialismo de supremacía blanca y las religiones sacrificiales de manipulación de masas- para beneficio de las élites y las minorías del poder.

Pensar así las prácticas narrativas permitirá potenciar entonces aquellos actos de contar historias como actos mesiánicos, subversivos del orden hegemónico y a la vez actos kairológicos, que instauran una temporalidad de la redención. Dichos actos han permitido a personas y pueblos subalternos, de todos los tiempos, imaginar y crear mundos nuevos, donde la justicia y la paz se encuentren como memoria dichosa del porvenir (con)traído en el tiempo presente, es decir, en el aquí colapsado de la historia de los vencedores, pero tiempo expandido por los sobrevivientes, con sus prácticas y narrativas de gratuidad y donación de vida para todas las personas.

\section{LA CRÍTICA BENJAMINIANA A LA FILOSOFÍA DE LA HISTORIA}

La filosofía de la historia en Occidente se vincula, en su fase narrativa surgida de la razón post-ilustrada de cuño marxista, con una filosofía política que asume la exclusión -y la lucha revolucionaria expresada en tanto escritura de la historia- como lugar de enunciación desde el que surgen otras narrativas, distintas a la que escriben los verdugos y vencedores ${ }^{11}$. Tal negatividad, como fuente de memoria histórica, se constituye -siempre desde el reverso de la historia oficial- como un principio de racionalidad emancipada, que hace

\footnotetext{
${ }^{10} \mathrm{El}$ argumento de Girard tiene vigencia para la filosofía de la historia en tanto el análisis de 10 real que es sacrificial. Ni racional, como lo planteó Hegel, ni trascendente, como lo planteó la onto-teología suareziana criticada por Heidegger. Se trata, por el contrario, de postular la validez del teorema antropológico mimético -que es imprescindible desplegar con todo su potencial epistemológico- para fundar una ética y una política de la imitación noviolenta en tiempos de violencia sistémica global, que ha identificado lo sagrado con el mercado. Véase R. GirARD - P. ANTONELlO - J. C. DE CASTRO Rocha, Evolution and Conversion. The Origins of the Culture (Continuum, London 2010) 244-249.

${ }_{11}$ Véase Reyes Mate (ed.), Filosofía de la historia, 276.
} 
posible la irrupción de lo mesiánico en términos políticos a partir de lo desechable ${ }^{12}$, lo invisibilizado y ocultado por la historia escrita por los vencedores.

Para evocar el trasfondo teórico del proceso de escritura de la historia desde su reverso, hay que considerar algunos ejemplos de cómo fue interpretado el tiempo mesiánico por Walter Benjamin, con sus alcances y sus límites propios. Esta interpretación ha tenido un fuerte impacto en América Latina, desde la obra de Miguel León Portilla en México -para escribir la historia de los vencidos de la conquista española del Anáhuac- hasta la historia de la Iglesia en América Latina propuesta por CEHILA, con fuerte inspiración de Enrique Dussel.

Primero, Benjamin sugiere la expresión de pasado maldito, es decir, aquel tiempo que ha sido negado por los vencedores, pero donde surge una interrupción mesiánica que queda en suspenso de temporalidad, tal como comenta Reyes Mate:

La relación creativa entre el pasado maldito y el presente necesitado es la substancia del carácter apocalíptico del tiempo. El Mesías significa la plenitud de los tiempos. Pero su llegada no se produce al final del tiempo, sino ahora, interrumpiendo el tiempo: "el Mesías interrumpe la historia; el Mesías no llega al final del desarrollo" $(1972,1,1.243)^{13}$.

Por otra parte, en este punto surge el debate crucial en torno a la interpretación benjaminiana de la "profanación" del tiempo mesiánico. Algunos autores como Reyes Mate y Enrique Dussel interpretan que tal profanación se da en relación al esoterismo y la mitología de las creencias hebreas, lo que a su juicio es la base de la secularización de la idea de redención. Así describe el filósofo español la apuesta benjaminiana para la superación dialéctica del mito judío por el logos moderno:

Benjamin es consciente de que su filosofar se alimenta de la tradición judía, que está literalmente embebida de ella (1972, 1, 1.235). Bebe, pues, de esa fuente, pero para profanarla. La profanación es un movimiento dialéctico que va de lo esotérico u oculto a lo exotérico o común. Dicho en otras palabras, Benjamin quiere hacer universal una experiencia que él ha observado en la tradición judía (hay más que propia experiencia: el convencimiento de que el sentido es un bien escaso y que solo se da en la relación, ahora sí dialéctica, entre mitos y logos) ${ }^{14}$.

\footnotetext{
12 "Podemos dar un paso más e identificar ese pasado oculto con el desecho de la historia (der Abfall der Geschichte). El historiador que es Benjamin no anda a la búsqueda y captura de lo más valioso, ni lo más llamativo: se fija en el desecho. La mirada de quien se dirige a la parte más oscura de la realidad recibe en premio una luz inédita para descubrir el presente" (Reyes MATE [ed.], Filosofía de la historia, 278).

${ }^{13}$ Reyes MATE (ed.), Filosofía de la historia, 279.

${ }^{14}$ Reyes MATE (ed.), Filosofía de la bistoria, 279.
} 
Esta lectura nos parece insuficiente porque reduce lo teologal ${ }^{15}$ a lo esotérico, por lo que se propone superarla a la hora de hacer nuestra propia interpretación teológica de la temporalidad kairológica. En este sentido, habría que aclarar -en primer lugar-en qué consiste la relación dialéctica, entre mythos y logos, de la que habló Benjamin. Es necesario recuperar su validez, no como "superación del mito por el logos", sino a partir de la afirmación de la correlación mostración-revelación, en cuanto lo desvelado-lo revelado, denotando así el fondo bumano-divino de la dialéctica entre mismidad y otredad, analizada como fenomenomenología de la subjetividad por Emmanuel Levinas.

En virtud de esta correlación fundacional de la redención en la historia, hablar de tiempo mesiánico no es un asunto de esoterismo ni de mythos, incluso si consideramos su relación dialéctica con el logos categorial de la filosofía occidental. Sino que, por el contrario, se trata de afirmar la especificidad teologal de lo revelado, que designa aquella exterioridad que funda la interioridad de la subjetividad. Una correlación metafísica y ética que -desde la racionalidad de Jerusalén- Hermann Cohen y Emmanuel Levinas pensaron "con la filosofía que se habla en griego" para traducir a pensamiento categorial occidental la universalidad de la Regla de Oro de la Torah: "Amarás al Señor tu Dios kamokha, como tú fuiste amado en Egipto" 16 .

Lo revelado es, pues, la gratuidad del don divino que irrumpe en la memoria de un pueblo esclavizado, que experimenta la liberación en tanto exterioridad que le adviene como redención humano-divina. $\mathrm{O}$, dicho de otra manera, la idea teológica de revelación designa la exterioridad del amor que nos es dado como fuente de interioridad y de intersubjetividad. En el seno de esta correlación fluye la dialéctica de mythos-logos como redención en el corazón de la historia y como memoria de los oprimidos que han vivido su liberación como logro histórico y, de manera concomitante, como don de anticipación mesiánica.

De ese hontanar divino-humano surge entonces la afirmación de la racionalidad de Jerusalén como inteligibilidad de la alteridad que redime y, en ese sentido, como una corrección a la racionalidad prometeica de Atenas marcada por la idea de mismidad. Se trata de aquella inteligibilidad de lo real destacada

15 Entendemos por teologal la vivencia originaria de la subjetividad en su religación con la fuente del ser, más acá de toda creencia y religión, susceptible de ser experimentada por cualquier persona en ámbito de su ser-en-relación.

16 Asumimos la traducción de la expresión hebrea kamokha ("como tú") propuesta por JeanMarie Vincent: "como tú fuiste amado en Egipto" porque despliega la fuerza contextual y performativa de la memoria hebrea, que le da identidad al pueblo mesiánico en proceso de memoria y liberación humano-divina. No se trata de un amor "como a ti mismo", sino de un amor de redención en la memoria de esclavos liberados que reconocen a los otros como prójimo. Véase J.-M. VINCENT, “"Tu aimeras ton prochain comme toi-même»? Lv 19,18b dans son contexte”, Revue d'Études Théologiques et Religieuses 81 (2006/1) 95-113. 
por Hermann Cohen como principio de otredad. La misma que también fue pensada como redención por Franz Rosenzweig y como ética del infinito por Emmanuel Levinas. Este es el corazón del argumento teológico para una lectura no reductiva del pensamiento hebreo, una pista que desarrollaremos aquí en su especificidad mesiánica hebrea y kairológica cristiana más adelante.

¿Cuál es entonces la intuición benjaminiana que es preciso rescatar en medio de los escombros de la secularización de lo mesiánico que vivimos en la segunda mitad del siglo XX? Nos parece que es la idea maestra es la "interrupción mesiánica" de la temporalidad lineal. Pero no en el sentido de una idea de apocalíptica judía -que apuntaba Reyes Mate, comentando a Benjamin - entendida como la lucha revolucionaria:

El concepto de interrupción resume la pointe política benjaminiana. [...] ¿Cuál es la propuesta de Benjamin? Sustituir la noción lineal del tiempo que vacía al presente de capacidad revolucionaria (la sociedad sin clases viene sólo al final) por la idea de que todo presente cuenta con el Umlaut: revolutionäre y que no es otra que la irrupción en el presente de un pasado inédito. Es la interrupción de los tiempos que corren. En otras palabras, "la sociedad sin clases no es el punto final (Endriel) del progreso en la historia, sino su lograda interrupción" $(1972,1,1.231)^{17}$.

Se trata más bien de encontrar esa otra manera de comprensión del tiempo, en cuanto interrupción de la fatalidad lineal de la historia de un futuro que nunca llega, gracias a la interrupción mesiánica relatada por la apocalíptica ciertamente, pero como narración de revelación:

En la apocalíptica judía se enseñaba que cada segundo "era la pequeña puerta por la que podía entrar el Mesías". Su reflexión personal [de Benjamin] sobre esa tradición le había llevado, por otro lado, a descubrir el mecanismo de transmisión de un bien tan escaso como es el sentido. No se produce sentido a capricho (mediante el trabajo, que dirían los marxistas) sino que se recibe del mito; el sentido no se desvela (Entbüllung), sino que se revela o manifiesta (Offenbarung): no lo creamos arbitrariamente, nos es dado en el origen. Su manifestación se produce en la "profanación" del mito que es un proceso de universalización de su significación ${ }^{18}$.

La idea teológica de revelación del tiempo mesiánico es, por tanto, el corazón de la intuición hebrea que alcanzó a otear Benjamin con dificultad, pero vaciándola de su sentido teologal. Esta inteligibilidad teológica es la que se aborda más adelante, desentrañando su potencial metafísico y epistemológico para nuestro contexto de resistencias, de parte de los sobrevivientes de la violencia sistémica de nuestro tiempo.

\footnotetext{
${ }^{17}$ Reyes MATE (ed.), Filosofía de la historia, 279. 281.

${ }^{18}$ Reyes MATE (ed.), Filosofía de la historia, 279.
} 
Pero antes volvamos a Walter Benjamin y Reyes Mate, autores que han influido de manera importante en el pensamiento latinoamericano y en los movimientos sociales revolucionarios de décadas pasadas (y pensamiento decolonial de años recientes). La filosofía de la historia -que surgió de esta lectura materialista del tiempo mesiánico- solamente alcanza a otear el instante por donde pasa el Mesías, pero sin captar la intensificación que se produce, en la vivencia de la temporalidad mesiánica, cuando se abre una grieta -a la experiencia de la redención- en el corazón de la historia rota de la humanidad:

Decía Benjamin que, en el tiempo judío, "cada segundo era la pequeña puerta por donde podía colarse el Mesías". La felicidad sólo entraba en el tiempo si había una hendidura por donde entrar. Sin hendidura no hay tiempo, pues decir tiempo es decir novedad y para que el novum ocurra tiene que romperse lo mismo de siempre. La continuidad es la matriz de la soledad y el tiempo rompe la soledad al posibilitar el encuentro de lo nuevo, es decir, de lo totalmente otro de nosotros mismos. Y, como dice Levinas, "lo totalmente otro, es el otro". Ni el dominio material del mundo ni el conocimiento del mundo nos liberan de la soledad, pues en ambos casos todo lo que encuentra es gracias a la luz del sujeto ${ }^{19}$.

La temporalidad mesiánica adviene, por tanto, en el "más acá" de la lucha revolucionaria, es decir, en la (inter)subjetividad posible como un modo de "revelación" en la historia, en tanto irrupción de la otredad del prójimo y de la Sofía divina como diferencia para el encuentro de "lo nuevo", que permite superar el solipsismo del sujeto egoico. Tal experiencia de redención es posible, en su sentido talmúdico, solamente como gesto mesiánico que anticipa la redención en el tiempo presente. Dicho gesto ético-político-espiritual es el que viven los tradikim, las personas justas de la historia, por quienes la humanidad se mantiene de pie en expectativa mesiánica, anticipando la redención. De esta manera, la revelación de la otredad de la historia es redención precisamente porque anticipa la justicia en la tierra como un fulgor o relámpago.

Pero ¿qué puede significar para la racionalidad moderno-tardía ese destello de la contracción del tiempo que produce el gesto mesiánico? Al respecto conviene recordar la influencia que tuvo Gershom Scholem en el joven Walter Benjamin, nutriendo su idea de justicia según las fuentes del Talmud, como lo subraya con gran precisión documental el investigador de Stanford, Peter Fenves:

En una entrada de su Diario con fecha de noviembre de 1916, Scholem hace el siguiente comentario sobre el concepto de esfuerzo en Benjamin: "La esencia de la noción judía de justicia como «el esfuerzo para llevar al mundo al más alto bien», como escribe Benjamin, revela en sí misma las palabras intraducibles de

${ }^{19}$ Reyes Mate (ed.), Filosofía de la historia, 279. 
los sabios, que [Immanuel] Hirsch cita: traddikim yachinu shechinah ba-aretz, que traduce él mismo con belleza de manera que una parte del significado con alguna precisión es reproducido, y parece que era familiar a Benjamin: «La justicia [nosotros preferimos decir 'los justos de las naciones'] prepara la tierra para que sea lugar donde repose lo divino». Eso es la justicia: hacer que la tierra sea el sitio de la Chekinah, para hacer bajar aquí la Chekinah" (S, 1: 4-19) ${ }^{20}$.

Solamente en esta hondura de la mística hebrea del "tiempo de los justos" es posible comprender la teología del tiempo mesiánico con sus implicaciones ético-políticas y espirituales en su fondo teologal, es decir, en la dialéctica mythoslogos, lo-humano-y-lo-divino, lo-develado-y-lo-revelado. Se trata de una perspectiva distinta a aquella visión de Atenas centrada en el tiempo lineal, e incluso diversa al eterno retorno de la racionalidad del eterno retorno, propia de Benares, postulada por Nietzsche.

Cabe señalar que Gershom Scholem fue consciente del insuficiente conocimiento de Benjamin sobre las raíces hebreas de la racionalidad de la otredad y la diferencia, tal como había sido argumentado por Hermann Cohen unos años atrás en su obra póstuma La religión de la razón desde las fuentes del judaísmo ${ }^{21}$.

$\mathrm{Al}$ respecto, Peter Fenves describe de la siguiente manera un pasaje poco conocido de la relación de Scholem con Benjamin:

Parece que Scholem hace una sugerencia similar a Benjamin, quien responde en la carta en la que anuncia la casi finalización de su "pequeño tratado" sobre el lenguaje y critica el "Concepto del tiempo en la erudición histórica" de Heidegger: “¿Qué significa Chekinah?” (GB, 1: 344). El hecho de que Benjamin se planteara tal pregunta indica el grado en que su punto de partida para una obra sobre la justicia difiere del de Scholem. [...] Benjamin recibe así una nota de reprobación, tal vez porque no sabía lo que significa Chekinah, o tal vez porque el concepto de esfuerzo se ha interpretado como un cierto "comportamiento". Pero, en cualquier caso, la insuficiencia de la definición de justicia, que Scholem asocia con las palabras intraducibles de los sabios, le da la oportunidad de comenzar de nuevo en la columna B con la declaración de que "el concepto de justicia gana su verdadero contexto en la filosofía de la religión" 22 .

${ }^{20}$ P. FEnVES, The Messianic Reduction. Walter Benjamin and the Shape of Time (University Press, Stanford 2011) 205-206 [traducción del A.].

21 Religion der Vernunft aus den Quellen des Judentum fue publicada en 1919. La traducción al castellano, preparada por el pensador y traductor mexicano Andrés Ancona, fue publicada en Madrid por Anthropos en 2004.

22 P. Fenves, The Messianic Reduction, 206 [traducción del A.]. Y en ese sentido continúa explicando Peter Fenves la implacable crítica de Scholem a la ignorancia de Benjamin de las categorías hebreas: “And in Scholem's point-by-point response to Benjamin's «Notes» the 
En suma, podemos decir que la cuestión metafísica y epistemológica del tiempo mesiánico aparece, con claridad meridiana, en este diálogo epistolar entre Gershom Scholem y Walter Benjamin como un destello en el pensamiento judío de las primeras décadas del siglo Xx. El concepto de justicia solamente será asequible en su verdad compleja desde la filosofía de la religión, entendida como pensamiento que surge de la "vida inreligionada", glosando la categoría propuesta por Andrés Torres-Queiruga. Es decir, desde la correlación que establecerá la justicia practicada por las personas justas de la historia como reflejo y destello de la gloria divina (kabod hebreo, doxa griega).

Tal es el centro vacio del argumento desarrollado en el último apartado de este artículo.

\section{UNA LECTURA LATINOAMERICANA Y MATERIALISTA DEL TIEMPO MESIÁNICO}

El argumento kantiano de la secularización de las convicciones religiosas traducidas a argumentos de razón como condición para el debate público, pareciera de validez para toda sociedad democrática, siempre y cuando no signifique la negación de la inteligibilidad de la revelación de la que son portadoras las religiones y sabidurías de la humanidad.

La versión benjaminiana de la secularización como profanación, tuvo influencia en una corriente importante de filosofía en la historia en América Latina, sobre todo con el pensamiento de Enrique Dussel y Bolívar Echeverría. Asimismo, caracterizó buena parte de la narrativa de los intelectuales materialistas de la región que acompañaron a los movimientos revolucionarios del siglo Xx, desde las guerrillas de los años sesenta a ochenta del siglo pasado, hasta los gobiernos de izquierda del nuevo milenio, pasando por la sociedad civil organizada en la lucha por los derechos humanos en las últimas décadas.

Para iniciar este breve repaso de los presupuestos principales de dicha secularización, hay que ver primero el caso específico de la filosofía de la liberación dusseliana, cuando asume explícitamente la teología política de san Pablo como una de sus fuentes. Al respecto, Dussel reinterpreta la "fe/emunab"

difference becomes visible. Under column B Scholem develops his own theory of justice as «the historical annihilation of divine judgment», whereas under column A he comments on Benjamin's «Notes»—but only to a certain extent. In the last of the five theses under column A, Scholem criticizes Benjamin's definition of the highest good: «In this sense, from the side of ethics, defining justice as the comportment [Verhalten] that makes the world into the highest good is thoroughly unsatisfactory.»" Dura crítica que le valdría a Benjamin el rechazo de su tesis de habilitación. 
en un sentido estrictamente materialista, vaciado de toda inteligibilidad teológica:

Sólo ahora podemos encarar el concepto de emunáh. Decir simplemente "fe" - considerando la historia de la inversión de los últimos veinte siglos de superposiciones interpretativas que han terminado por sepultar su significado- es caer en un equívoco total. Además, aplicando el método hermenéutico que pasa de la metáfora, o el relato racional simbólico, a su contenido categorial, la cuestión exige tener suficiente creatividad para descubrir nuevas capas semánticas. Como hemos tantas veces repetido, el criterio tradicional de justificación era la Ley. Ahora, la comunidad mesiánica, el resto, descubre una nueva fuente de legitimación. Proponemos que se trata (para la filosofía política y decantando el símbolo) del nuevo consenso crítico de la comunidad mesiánica ante el derrumbe de la Ley. La comunidad mesiánica, el pueblo, ante el inmenso poder del Imperio romano, del templo (de Israel), la tradición (de los recientes cristianos que no pueden superar sus antiguos ritos, costumbres, sacrificios, etc.), se atreve, sin embargo, a enfrentarlo desde su certeza de poseer una convicción que puede transformar la totalidad de la realidad ${ }^{23}$.

En esta lógica que pretende interpretar la "profanación" benjaminiana en contexto de transmodernidad, Dussel interpreta la fe de la comunidad mesiánica en clave política como fidelidad intersubjetiva del "pueblo", pero sin referente alguno al Reinado de Dios ni al cuerpo del Mesías, ni a la potencia de la Ruah que lleva a término este alumbramiento escatológico. De ese mismo presupuesto el pensador argentino-mexicano deriva una lectura de la justificación por la fe, vaciada de todo su contenido teologal, en términos de legitimación del futuro sistema que instaura la revolución:

Esa certeza, ese consenso crítico de la propia comunidad, es lo que se denomina emunáb en hebreo (אמונה) o pistis (ríotıc) en el griego de Pablo, que podría describirse como la certeza entusiasta de la comunidad crítica (cuya fuente se encuentra en el mismo pueblo), como la mutua confianza que se continúa en el tiempo (kairós) como fidelidad intersubjetiva de los miembros de una tal comunidad, convencidos de la responsabilidad solidaria en la realización de un nuevo acuerdo, contrato o Alianza que legitima o justifica ("juzga como justo") la arriesgada praxis en el extremo peligro del "tiempo mesiánico" (de un Walter Benjamin) y como fuente de legitimación del futuro sistema (y en esto nos separamos de Agamben). Esto es lo que, pienso, debe entenderse en filosofía política como "la justificación por la fe" 24 .

${ }^{23}$ E. D. DussEL, Filosofías del sur: descolonización y transmodernidad (Ediciones Akal, México 2015) 122-123.

${ }^{24}$ E. D. Dussel, Filosofías del sur: descolonización y transmodernidad, 125. 
Pero la fe en tanto virtud teologal propia de la subjetividad abierta a la otredad, así como la justificación por la fe, la gracia y la redención, son todas ellas categorías teológicas -y no meramente símbolos de una religión que hay que convertir en categorías políticas, como propone Dussel- de una inteligibilidad de lo real donde acontece la redención como experiencia humano-divina del ágape del mesías, desde el reverso de la historia ciertamente, donde Dios actúa para comunicar vida plena.

Por ello, la interpretación filosófico-política como “innovación” semántica de Dussel sobre la fe y la justificación por la fe son, a nuestro juicio, un ocultamiento del sentido mesiánico, kairológico y escatológico de la racionalidad de Jerusalén llevada a una radical expresión por el cristianismo.

Como corolario de su argumentación, Dussel critica el argumento de autores críticos de la secularización cumplida en el razonamiento de Benjamin, que buscan -como nosotros aquí- mantener vigente el reducto escatológico del judaísmo y del cristianismo como conocimiento de lo real. Así, por ejemplo, Dussel intenta desmantelar el argumento de la ortodoxia radical:

Hay entonces una tendencia a recuperar la "herencia cristiana" — ante el secularismo y un cierto judaísmo anticristiano-, en la que se encuentra igualmente G. Vattimo, completamente diferente al movimiento de la Teología de la Liberación latinoamericana (pero igualmente islámica, judía, budista, etc., y la Política de la Liberación) que sitúa su posición (locus enuntiationis) en una actitud "mesiánica" (crítica ante el orden vigente, "de la Ley") definiendo a los antagonistas dentro del bloque en el poder mundial, nacional, capitalista, machista, racista, etc. A esta última no le interesa recuperar la herencia de la cristiandad, que con S. Kierkegaard es interpretada como la inversión del cristianismo. Le interesa sí recuperar el cristianismo-judío, de Jeshúa ben Josef, de los Sinópticos, de Pablo, que se abrió universalmente a los goím desde los primeros siglos anteriores a Constantino, y antes de la "restauración" de la Ley como criterio de "justificación" con Teodosio (el derecho romano cristiano: desde ese momento se podrá "matar" en nombre del crucificado, y Lucifer, Cristo, será remitido en el "infierno" (véase F. Hinkelammert, Sacrificios bumanos y sociedad occidental. Luifer y la bestia [San José, DEI 1991]). Por ello Nietzsche, que en sus piruetas grandilocuentes se descubre como el Anticristo, al oponerse a ese Pantokrator, Cristo-Emperador o el nuevo fetiche, apenas si recupera algunos atributos, muy deformados, de la criticidad del Khristós histórico crucificado). ¿Para qué recuperar la herencia de la larga inversión? Mejor poner de pie lo que siglos pusieron de cabeza ${ }^{25}$.

Pobre corolario de un análisis filosófico materialista. Nosotros también buscamos recuperar no solamente la "actitud mesiánica", sino la temporalidad kairológica como inteligibilidad teológica de la redención de la historia violenta de

${ }^{25}$ E. D. DusSEL, Filosofías del sur: descolonización y transmodernidad, 139, nota 89. 
la humanidad con su dimensión ética, política y espiritual. Se trata de todo un dinamismo antropológico que es asequible a toda subjetividad en tanto vida teologal -un modo específico de decir con lenguaje teológico la irrupción del mesías en las grietas de la historia- como dinamismo que despliegan las personas justas de la historia. Esa fuerza histórica que despliegan los pobres de YHWH en la historia del pueblo hebreo, se continúa y radicaliza en la comunidad mesiánica que de manera radical sigue los pasos de Jesús de Nazaret, confesado luego de su ejecución en una cruz como "primer nacido de entre los muertos" (Col 1,18).

Desde ese hontanar de vida -entregada por la comunidad mesiánicaseguimos afirmando que las personas justas de la historia mantienen de pie a la humanidad herida gracias a sus actos de justicia y de amor de donación, por los que nos permiten vivir el tiempo presente con esperanza en la redención humano-divina.

\section{Sobre la filosofía mesiánica de la historia más allá de Benjamin y Dussel}

La filosofía de la historia posterior a Kant y Hegel fue construyéndose sobre el postulado de la secularización de la idea de redención, la cual había dado consistencia al pensamiento político medieval y renacentista, prolongándose hasta la teoría política barroca donde el Estado se encontraba supeditado a una idea de justicia trascendente. Una vez consumada la revolución antropocéntrica en la idea de la justicia, la filosofía de la historia seguiría los mismos derroteros, concentrando su interpretación de la historia como memoria de los vencedores, con dominio del sentido de la historia marcando una narrativa hegemónica, típica de la razón ilustrada, en específico, de la razón instrumental.

Como ya mencionamos antes, según Dussel el argumento kantiano de traducir las creencias religiosas en argumentos de razón significó la negación de las "narrativas simbólicas" propias de las religiones:

El reto presente es el de extraer esas anquilosadas narrativas simbólicas ("teológicas" para el secularismo jacobino ilustrado) que residen y se estudian en la facultad de teología para situarlas por primera vez también en la facultad de filosofía. Consistiría en efectuar sobre ellas una hermenéutica, una interpretación "estrictamente filosófica". Y aún, trascendiendo las meditaciones kantianas sobre el asunto, deseamos aclarar de manera diferente y con mayor precisión el asunto [...] pueden interpretarse filosóficamente; tomar el texto o la narrativa racional en base a símbolos a fin de descubrir su sentido último racional y las categorías implícitas teórico-universales que incluye -que Kant 
denomina "conceptos determinados de la razón" (c.2), en vista de una comunidad secular ${ }^{26}$.

Pero aquí precisamente radica el equívoco que, a nuestro juicio, ha presidido la recepción benjaminiana en contexto latinoamericano, a saber, en confundir el mito religioso con la inteligibilidad de las fes, en este caso hebrea, que tienen un potencial semántico que es preciso universalizar con categorías filosóficas, sin negar el significado trascendente de sus narrativas e ideas religiosas y, por lo mismo, afirmando la inteligibilidad teológica de lo real.

De otro modo, como lo veremos ahora, caemos en el reduccionismo dusseliano que hace del tiempo mesiánico un asunto de política de la liberación en clave materialista:

Es decir, tomaremos las narrativas simbólicas (a), que no deben ser trabajadas hermenéuticamente solas en la facultad de teología (b.1), y las localizaremos en la facultad de filosofía (b.2) para efectuar una labor interpretativa filosóficopolítica (b.2. $\beta$ ), de la que trata una política de la liberación estrictamente filosófica. Es decir, no se trata de una recuperación filosófica de la teología, sino de la recuperación para la filosofía de textos fundacionales que poseen implícitamente categorías críticas que originaron una cultura (la de las cristiandades oriental y occidental, incluyendo la Moderna europea), y que pueden construirse como categorías filosóficas críticas de gran pertinencia en el presente ${ }^{27}$.

Esta interpretación condujo a Dussel, como ya vimos, al reduccionismo político de la antropología paulina que, si bien surge como una crítica a la decadente moral del imperio romano, no se limita a ella:

Desde este masivo sufrimiento de la subjetividad carnal viviente de las multitudes del Imperio fue desde donde se escribieron esas cartas paulinas a "comunidades éticas" (como las denominaría Kant), a fin de que tomaran conciencia intersubjetiva crítica y actuaran en consecuencia (es una propuesta teórica en función de una praxis liberadora, crítica, transformadora) ${ }^{28}$.

El sufrimiento que caracteriza la vivencia del tiempo mesiánico pierde su radicalidad existencial propia que es del orden escatológico, pero no como visión de los tiempos futuros, sino como interrupción de la violencia sistémica a partir del gesto mesiánico que abre una grieta en el ciclo fatal del tiempo lineal para introducir en la historia destellos de redención por medio de los tradikim o las personas justas de la historia.

\footnotetext{
${ }^{26}$ E. D. DusSEL, Filosofías del sur: descolonización y transmodernidad, 106-107.

27 E. D. DusSEL, Filosofias del sur: descolonización y transmodernidad, 109-110.

${ }^{28}$ E. D. DussEL, Filosofías del sur: descolonización y transmodernidad, 113.
} 


\section{Sobre la episteme teológica}

El giro kantiano fue decisivo para la consumación de esta reducción antropocéntrica de la filosofía mesiánica de la historia porque, bajo pretexto de objetividad de argumentos racionales, desconoció el estatuto epistémico de la teología como un modo de conocimiento de lo real (en su caso a partir de la revelación hebrea y cristiana), un conocimiento sub specie aeternitatis, como solía decir Tomás de Aquino en plena Edad Media.

Si bien, el juicio epistemológico derivado de la revelación bíblica fue el gran campo de investigación de la teología universitaria naciente en la Edad Media -en contexto judío, cristiano y musulmán- su correlación con la razón moderna fue siendo cada vez más controvertida hasta llegar a ser incompatible, en parte por las ideologías enfrentadas entre religiones institucionalizadas y academias científicas nacientes, pero también debido al endiosamiento de la razón ilustrada, en sus diversas fases modernas, desde el empirismo hasta el positivismo y la racionalidad tecno-científica de nuestros días.

Como parte de este progresivo reduccionismo epistemológico, cada vez había menor cabida para una teología de la historia, según la tipología moderna que, entre otros, analiza Reyes Mate:

El "principio de razón" lo que plantea es la relación entre pensamiento y realidad. Esa relación se puede concebir de tres maneras: a) el "modelo hegeliano" en el que lo real es racional; lo real está en sí sometido a la estructura ontológica; b) El "modelo heideggeriano" según el cual la existencia no se compadece con el "principio de razón"; mejor se la define con términos tales como "diferencia", "misterio", etc.; c) El "modelo kantiano" para el que lo real, sin ser en sí exhaustivamente racional -es decir, idéntico a la estructura ontológica-, es, de todos modos, racionalizable hasta el punto de utilizar la estructura ontológica para explicar lo real no tanto con la pretensión de desvelar así los secretos de la realidad cuanto, más bien, para indicar hacia dónde podría dirigirse la acción humana ${ }^{29}$.

Solamente en el modelo heideggeriano habría cabida para una racionalidad teológica, pero solamente reconocida en cuanto temporalidad kairológica subsumida como devenir del Dasein, ya depurada de su carga escatológica específica. En efecto, el tiempo kairológico en Heidegger es el acontecimiento de la vida fáctica, con su carga mistérica y su devenir del ser arrojado en el tiempo. Pero no queda ya rastro alguno de redención humano-divina, esa correlación establecida por la racionalidad de Jerusalén como "hontanar de la religión de la razón” en expresión de Hermann Cohen.

${ }^{29}$ Reyes MATE (ed.), Filosofía de la historia, 15. 
La cuestión sobre el sentido de la historia quedó así supeditada al afán de poder de la razón instrumental, con su nuevo mito del progreso por la técnica y de la idea maestra del futuro lineal de la historia en virtud del progreso. Y en la versión de Heidegger se trató de un sentido de la historia como devenir del Dasein en la soledad de la palabra y del ser-para-la-muerte.

Pero no podemos olvidar que la teleología hebrea como cristiana no es como la racionalidad de Atenas, que ubicaría el telos en un fin cronológico. Se trata de la diferencia de la racionalidad de Jerusalén, subrayada con vigor por Hermann Cohen: el tiempo mesiánico hebreo es una interrupción del tiempo lineal y cronológico, en tanto irrupción de otra temporalidad a partir del gesto mesiánico que recordaba el Talmud: "el mesías llegará cuando te quites el pan de la boca y lo des a quien tiene hambre".

En este sentido, postulamos aquí que la teología mesiánica hebrea trata la historia -ya desde el éxodo de Egipto hasta el retorno de Babilonia- como una experiencia de anticipación del futuro en un presente contraído que genera un hábitat para un pueblo en diáspora, pero sostenido por tres referentes de sentido, a saber, tierra, templo y Torah. Ciertamente estas mediaciones simbólicas con el tiempo se irán esclerosando, como ídolos inertes, en tanto que se desligaron de su fondo experiencial de resistencia. Pero persisten como metáforas vivas de la experiencia de la redención para el pueblo mesiánico, en la perspectiva del pueblo de Israel como primogénito de muchos pueblos que incluye así a toda la humanidad.

En suma, la filosofía del tiempo mesiánico propuesta por Benjamin retomada por Reyes Mate en contexto iberoamericano- no da cuenta de la hondura ontológica y epistemológica de la temporalidad mesiánica, pues desconoce el fondo existencial de la redención donde lo divino encuentra lo humano en el seno de actos y gestos mesiánicos de redención. Tal será el enfoque que desarrollaremos en la última parte de este artículo.

\section{RECUPERANDO LO REAL TEOLOGAL ${ }^{30}$ COMO INTELIGIBILIDAD KAIROLÓGICA}

De esta manera llegamos así a la parte central del argumento, sobre la temporalidad mesiánica que deviene kairológica gracias a Jesús de Nazaret y la

\footnotetext{
30 Seguimos una pista distinta, pero convergente, a la planteada por Iván Illich en esa obra preparada al final de su vida con David Cayley sobre el humus teológico de su pensamiento. En particular nos inspira su modo de comprender la verdad de la encarnación como una disrupción de la historia: "Creo que la Encarnación hace posible un florecimiento inédito y sorprendente del amor y del conocimiento. Para los cristianos, el Dios bíblico ahora puede ser amado en la carne [...] Una nueva dimensión del año se abre ante nosotros, pero esta
} 
comunidad de discípulas y apóstoles en la Galilea de los gentiles, que tiene un final dramático en la muerte en cruz de su rabí. En medio de este duelo, inspiradas en el testimonio y la narrativa de redención del éxodo de Egipto que fue el crisol epistémico de la tradición hebrea- las comunidades paulinas primitivas radicalizan la experiencia de los justos aniquilados a partir de su idea de kairós, o tiempo oportuno donde acontece la redención. Se trató de descubrir la verdad del nuevo anuncio: la redención que acontece por medio de un mesías crucificado que es "skandalon para judíos y necedad para griegos"

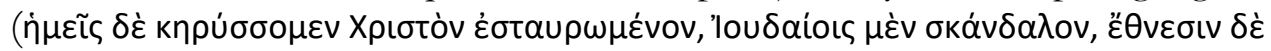
$\mu$ wpiav) (1 Cor 1,23).

En el seno de ese credo primitivo paulino yace la confesión en la vida del Justo que vive en medio de una "dialéctica" de redención: por un lado, aniquilado por los humanos, pero por otro, vivificado por su Abbá. En ese sentido, la confesión en la resurrección de los muertos surgirá como confianza en el cumplimiento de la promesa hecha a Israel en Egipto como a los tradikim, realizándose esta "contracción del tiempo" con Jesús de Nazaret como primer "Crucificado-que-despertó", según el testimonio de su comunidad mesiánica de sobrevivientes ${ }^{31}$ :

El Ángel se dirigió a las mujeres y les dijo: "Ustedes no teman, pues sé que buscan a Jesús, el Crucificado; no está aquí, ha despertado, como lo había dicho.

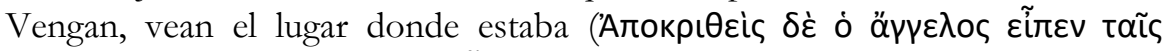

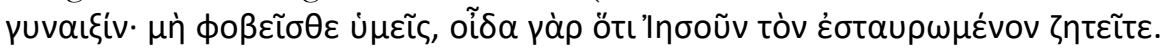

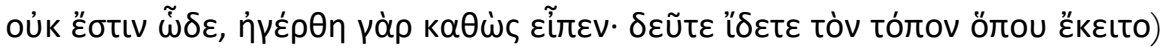
(Mt 28,5-6a).

Esa temporalidad mesiánica deviene ahora kairológica. Pero fue leída en la filosofía de la historia del siglo xx -como ya vimos antes- en clave de redención política intramundana por la teoría revolucionaria de cuño benjaminiano. En ese contexto, la teología de la historia -como redención disruptiva del tiempo cronológico- fue puesta en suspenso para dar paso a una lectura revolucionaria del mesianismo, que acontece en las rupturas de la

apertura es extremadamente ambigua debido al modo en que hace estallar ciertos supuestos universales sobre las condiciones bajo las cuales es posible el amor. [...] creo que puedo demostrar que la encarnación del Allah bíblico, coránico y cristiano representa un punto de inflexión en la historia del mundo, tanto para creyentes como para no-creyentes. La creencia se refiere a lo que sobrepasa la Historia, lo que la excede, pero también ingresa en ella y la transforma irremediablemente" (I. ILLICH, Los ríos al norte del futuro. Conversaciones con David Cayley [Alios Ventos, México 2020] 92. 93).

${ }^{31}$ Idea que desarrollo en el primer volumen de la trilogía sobre la idea de tradición: C. MendozaÁlvarez, La resurrección como anticipación mesiánica. Duelo, memoria y esperanza desde los sobrevivientes (Universidad Iberoamericana, México 2020). 
historia hegemónica instauradas por las insurrecciones mesiánicas de los excluidos por los sistemas de opresión.

En su sentido filosófico, la cuestión del universal concreto fue el telón de fondo de aquella idea de temporalidad mesiánica que asumió de manera restrictiva la modernidad. En efecto, en el contexto de la idea hebrea de redención -pensada con rigor filosófico por Franz Rosenzweig en los inicios del siglo XX- la pregunta ética y epistemológica consistía en saber si la experiencia particular de un pueblo de esclavos podía ser principio universal de acción y de conocimiento de lo real en tanto sentido de la historia.

Cabe recordar aquí que, ya desde Aristóteles hasta Tomás de Aquino, la cuestión del universal concreto había sido ampliamente debatida, hasta llegar a la síntesis tomasiana de que lo particular puede ser universal en tanto que signifique la "sustancia" de lo predicado a través de una multiplicidad de "accidentes". Lo difícil es discernir qué es lo sustancial, por ejemplo, en el caso de la experiencia de liberación de un pueblo esclavizado en Egipto que pueda ser "universalizable" a otras circunstancias históricas. De ahí la necesidad de la alegoría, la metáfora y la analogía para establecer las relaciones de proporcionalidad e inteligibilidad entre los términos propuestos y, sobre todo, entre sus relaciones. En este sentido, la filosofía de la historia de la redención se expresaba como tradición, en tanto práctica hermenéutica con capacidad de establecimiento de tipologías con alegorías, metáforas y analogías que postularían criterios de verdad para una comunidad de intérpretes reconocidos como sujetos de esa tradición.

Con este planteamiento se propone aquí la idea de que el problema de la filosofía de la historia - que reconozca su relación con la teología de la historiaapunta a una cuestión de fondo que es de orden metafísico y epistemológico, por lo que no solamente se trata de un asunto de conflicto de interpretaciones entre fanatismo religioso y razón moderna, sino de una cosmo visión/cosmo vivencia humano-divina en juego, y de una epistemología de lo inmanentetrascendente fundada en una correlación imprescindible para la siempre inacabada comprensión de lo real diverso.

Con el fin de resolver el problema de la reducción epistemológica de la idea de tiempo mesiánico es crucial comprender ese trasfondo metafísico y epistemológico de la cuestión, a fin de establecer las condiciones de posibilidad en tiempos posmodernos del antiguo axioma "todo lo real es teologal", en su sentido metafísico (no onto-teológico como criticó Heidegger con toda razón) y epistemológico, pero ahora en tiempos de modernidad tardía, aquella que ya tiene suficiente distancia crítica de sus propios reduccionismos ilustrados. 


\section{Sobre la teología del tiempo mesiánico y kairológico}

La hipótesis radica, por tanto, en la afirmación de que lo teologal es la expresión de lo universal concreto de la redención, cuyas metáforas y analogías fundacionales son dos: (1) el éxodo del pueblo hebreo de Egipto; y (2) el testimonio de las narrativas de la resurrección (tumba vacía y apariciones) de Jesús de Nazaret, "un crucificado que despertó", según testimonio de la comunidad jesuánica, como fue analizado en pasadas investigaciones.

Primero se explorarán algunas condiciones de posibilidad de esa radical vivencia de temporalidad kairológica que hacen posible las personas justas de la historia, dando paso a una vivencia performativa de redención. Lo hacen por medio de prácticas y narrativas surgidas desde las subjetividades en resistencia contra la violencia sistémica de cada tiempo, instaurando nuevas formas de intersubjetividad en medio de los intersticios de la violencia sistémica que abren paso a la esperanza como horizonte de redención en el corazón de la historia.

Se propone mantener la singularidad de la vivencia de los excluidos en su relación con Dios eterno -la Sofía divina que las teologías feministas rememoran como narrativa contrahegemónica al patriarcado- por dos razones principales:

(i) porque de las narrativas de los pobres, excluidos y víctimas en resistencia surge el sentido de la redención como crítica éticopolítica-espiritual al sistema de dominación, en nombre y memoria de la presencia amorosa inefable que les habita e impulsa a ir más allá del resentimiento y la venganza;

(ii) y porque sus resistencias generan la potencia de re-escribir un pasado que les fue negado y manipulado (por ejemplo, en México, la "verdad histórica" de Ayotzinapa impuesta por el Estado), aconteciendo así la "interrupción del tiempo lineal" y la "revelación" del tiempo kairológico.

Pero este proceso de temporalidad mesiánico-kairológica acontece no solamente como un acto político, aunque sin duda tiene expresiones de ese orden como son las resistencias que crean autonomías territoriales, epistémicas y espirituales de subjetividades y pueblos en resistencia. Sino que esas resistencias tienen su fuente en una vivencia teologal de irrupción de la redención (promesa cumplida del Otro en les otres reconocides) en el seno de la historia rota y hecha añicos por la codicia de los verdugos, pero en cuyas grietas brota la revelación del nombre divino como correlato de los nombres humanos remembrados. 
Esta cualidad disruptiva del tiempo mesiánico -más allá del marco sujetoobjeto- había sido captada por Benjamin, aunque luego subordinada al ámbito político como interrupción revolucionaria. Sobre aquella noción benjaminiana del tiempo mesiánico, como "tiempo-tiempo" o "tiempo-por-venir" que aquí rescatamos en su sentido teológico, explica Peter Fenves:

Si los términos filosóficos tradicionales pueden ser usados para capturar el carácter del tiempo, sin revelar su forma, serían aquellos a través de los cuales Benjamin determina la tarea más alta de la filosofía venidera: la de identificar "una esfera de total neutralidad en relación con los conceptos de objeto y sujeto" (2:153). Así concebido, el tiempo mesiánico no es otro tiempo; es sólo tiempo-tiempo y nada más que tiempo "plástico". El carácter paradisíaco del espacio, hacia el que tiende el plano pictórico, concuerda con el carácter mesiánico del tiempo, que por lo tanto está cargado de tensión y puede llamarse "pleno" porque cada tramo de tiempo contiene todo el tiempo. En "Mundo y Tiempo" Benjamin dice de la primera categoría: "no hay nada continuo" (6: 99); la condición opuesta caracteriza al otro concepto considerado, a saber, el tiempo, que, como sugiere brevemente Benjamin, debería denominarse en realidad "el mundo venidero". En virtud de su continuidad no direccional, el tiempo -"convertido" en "ahora"- es el "mundo venidero" 32.

De esa vivencia de temporalidad anclada en el presente se deriva también aquella otra idea tan sorprendente de Benjamin sobre la "plasticidad" del tiempo mesiánico, en tanto "tiempo ahora", como comenta con agudeza Esther Cohen:

Benjamin emprende la construcción de un nuevo y original emplazamiento filosófico cuya fuerza radica en la plasticidad de un concepto comprensivo de historia que por una parte se deslinda radicalmente de la idea de progreso, del tiempo absoluto y del continuum de la historia relato y que, por otra, adopta como posición de discurso la "visión de los vencidos", reivindica como estrategia cognoscitiva la intuición instantánea ("Sólo en la imagen, que relampaguea de una vez para siempre en el instante de su cognoscibilidad, se deja fijar el pasado") (117) y propone una noción de temporalidad, el "tiempo que en articulación dialéctica actual" o "tiempo ahora", con el "tiempo mesiánico": 1) "resume en una grandiosa abreviación la historia entera de la humanidad" (140), 2) hace saltar el continuum de la historia reivindicando el presente como tiempo único y estático y 3) restituye al futuro sus cualidades esenciales: la indeterminación y la imprevisibilidad ${ }^{33}$.

Con estas intuiciones, Benjamin se acercaba al tiempo teológico, pero solo alcanzando a vislumbrarlo, como Moisés frente a la tierra prometida. No se

\footnotetext{
32 P. Fenves, The Messianic Reduction, 238.

33 E. COHEN (ed.), Walter Benjamin: fragmentos críticos (Universidad Nacional Autónoma de México, México 2016) 265.
} 
atrevió a entrar en ese mysterium de la temporalidad del tiempo consumado, en tanto promesa cumplida, que el cristianismo llevará a su más radical expresión con la fe en la resurrección de los muertos. Sobre el tiempo teológico benjaminiano, Esther Cohen agrega una precisión valiosa sobre el arrobamiento místico, con gran acierto epistémico y conocimiento de las fuentes hebreas:

Con el objetivo de superar filosóficamente lo que de corrompido e inútil portan el marxismo vulgar, el historicismo y el positivismo en sus versiones contemporáneas, Benjamin introduce un dispositivo conceptual en el que incontestablemente cohabitan nociones propias del materialismo y expresiones que provienen directamente de la tradición teológica judía, específicamente las que se refieren al tiempo mesiánico que se articula con una idea del pasado "que contiene un índice temporal que lo remite a la salvación" (112) y con una idea del presente asumido como tiempo-abora cuya sustancialidad, no transitoria y efímera, sino estática (ni más ni menos la del arrobamiento místico) revela la apertura e indecibilidad del futuro, porque en un futuro así concebido "están dispersas las astillas de un tiempo mesiánico" (141) y junto a ellas la esperanza de la redención, ya que en él "cada segundo es una pequeña puerta por la que puede entrar el Mesías" (142) 34 .

Llegamos así al corazón de la teología del tiempo mesiánico en su cualidad de rememoración (zakhor), categoría central de la teología hebrea del recuerdo (zikkaron) de la pascua de Egipto como actualización del pasado liberador en el presente como tiempo contraído. De nueva cuenta, Esther Cohen calibra de manera adecuada a nuestro juicio el sentido teológico político de la redención:

[...] el análisis igualmente constata la inserción y la presencia activa, al interior de un discurso inequívocamente crítico negativo, de categorías y nociones provenientes de la tradición teológica judía: especialmente de aquellas formulaciones que por referirse expresamente al tiempo mesiánico y la rememoración de la forma y el sentido últimos del conocimiento histórico o a la rememoración (zakhor) como redención de los oprimidos del pasado como restitución y pago de una "promesa de felicidad" hasta ahora incumplida conservan una evidente connotación mesiánica (véase: Scholem, 2000). Lo que ya no parece tan seguro es que dicha inserción y esa presencia soporten adecuadamente la idea de que "Benjamin es marxista y teólogo" (Löwy: 41) ${ }^{35}$.

En suma, con Benjamin se vislumbra ya en el horizonte lejano una teología de la historia como redención en tanto que temporalidad mesiánica cumplida:

En Benjamin, lo característico es que dicha promesa se enuncia explícitamente como redención; es decir, con un término tomado directamente del discurso teológico, específicamente mesiánico, cuyo sentido implica una enuncia asimismo con otro término teológico: recuperación del pasado que es su

\footnotetext{
${ }^{34}$ E. COHEN (ed.), Walter Benjamin: fragmentos críticos, 266.

${ }^{35}$ E. COHEN (ed.), Walter Benjamin: fragmentos criticos, 266-267.
} 
rememoración (zakhor); y en donde ambos términos se disponen en un horizonte temporal que supera filosóficamente la noción absoluta, lineal y siempre progresiva del tiempo newtoniano (modelo fundamental del relato de los vencedores y sus presuntas "leyes históricas") para poner en su lugar la noción de un tiempo presente o tiempo ahora en el que el historiador debe "fijar la imagen del pasado tal como esta se presenta de improviso al sujeto histórico en un momento de peligro" (118), y en donde por cualquier "pequeña puerta" puede suscitarse la interrupción revolucionaria de un proceso histórico que, en sus términos actuales y desde la perspectiva de los vencedores, a la manera de una tempestad arrastra a la humanidad hacia un futuro catastrófico, mientras a los pies del ángel de la historia "no dejan de acumularse escombros"36.

Pero esta temporalidad benjaminiana roza apenas la dimensión kairológica, porque sigue en suspenso el cumplimiento de la promesa.

El "salto mortal" a la vivencia del kairós lo dará el cristianismo primitivo, sobre todo en la lectura paulina, que recibe y construye la revelación de la resurrección como expresión radical de la nueva temporalidad kairológica. Es en el memorial del Crucificado-que-despertó donde acontece la redención como promesa cumplida de vida plena para las personas justas de la historia (tradikim), y las que fueron aniquiladas que ahora son rescatadas del sinsentido, del olvido y, por ello, de la muerte, por el Abbá de Jesús en la fuerza de su Ruah como aliento de vida plena.

En el corazón de este anuncio estará la experiencia de una comunidad mesiánica en duelo, resistencia y memoria que, en el tiempo de ahora (kairós) atraviesa la grieta, abriendo un intersticio en el muro del odio y la exclusión para anunciar que la redención ya se está cumpliendo en el aquí y el ahora.

De ese manantial surge la inspiración para la narrativa mesiánica y kairológica de las víctimas de todos los tiempos que convierten su opresión en praxis de sobrevivientes con dignidad, memoria y esperanza.

Tal es el don de la sobreabundancia divina - del misterio divino como fuente y no como super ente- que redime a la historia de su contradicción de muerte como promesa que se está cumpliendo en la rememoración de los tradikim que hacen los sobrevivientes de las violencias históricas, haciéndose cargo de la realidad de vida como resistencia con memoria, dignidad y esperanza.

\section{COROLARIO: EL TIEMPO MESIÁNICO Y LAS PRÁCTICAS NARRATIVAS}

¿Cómo se relacionan la filosofía del tiempo mesiánico y la teología del tiempo kairológico con las prácticas narrativas de las víctimas de hoy?

${ }^{36}$ E. COHEN (ed.), Walter Benjamin: fragmentos críticos, 267-268. 
Si se parte del principio de que las víctimas son quienes mejor conocen su propia historia y que la práctica ética y po(ética) de la escucha ${ }^{37}$ son elementos esenciales de las prácticas narrativas ${ }^{38}$ como metodología de re-escritura de la historia desde abajo y desde su reverso, entonces surge un fondo común con el tiempo mesiánico-kairológico. A nuestro entender, ese fondo es la vivencia originaria que comparten: subjetividades vulnerables y vulneradas que viven el tiempo presente como sobrevivientes de experiencias de violencia y aniquilación, pero en el seno de las cuales brota un manantial de dignidad, indignación y resiliencia que, poco a poco, va transformándose en resistencia, compromiso social y esperanza viva.

Se describe aquí, a modo de corolario, esos "momentos fenomenológicos" de la constitución de la (inter)subjetividad que hacen posible las víctimas convertidas en testigos. De esta manera, devienen referente de una filosofía de la historia post-secular, que da cabida a la teología de la redención aquí dibujada en sus referentes fundantes. Esos momentos designan, al menos, tres nudos de relaciones: (i) vulnerabilidad, (ii) memoria y (iii) esperanza.

(i) Vulnerabilidad

La constitución de la (inter)subjetividad es un proceso relacional siempre inacabado por el que nos vamos constituyendo personas en tanto seres-enrelación. La cualidad ontológica de ser-abiertos a la relación de otredad fue explorada por Emmanuel Levinas en cuanto relación ética anterior a toda ontología y toda moral. Pero también fue pensada en su carácter mimético violento por René Girard, en tanto proceso de deseo de imitación siempre marcado por el doble mimético, el contagio del mecanismo victimario y la falsa salida del sacrificio que se instituye como racionalidad violenta, consagrada por Hegel como ley de la historia a juicio del pensador de Aviñón.

Esa vulnerabilidad se torna así subjetividad vulnerada cuando queda marcada por la violencia sacrificial que puede expresarse en ritos diversos, animistas como el chivo expiatorio, religiosos como la abnegación religiosa, o seculares como la invisibilización del otro diferente. Al fin y al cabo, procesos de negación de las subjetividades diversas en aras de una "paz" cada vez más precaria.

De ahí que la vulnerabilidad sea el lugar fenomenológico fontal donde acontece el tiempo mesiánico. Esto significa que la vida de los tradikim produce la interrupción del tiempo lineal de chronos-ese dios que devora siempre a sus

\footnotetext{
37 Véase N. A-A, "Moradas del ser. Notas sobre arte y testimonio en el pensamiento de Hannah Arendt y la escritura de Nora Strejilevich", América Latina Hoy 78 (2018), en línea: https://revistas.usal.es/index.php/1130-2887/article/view/alh2018787386 (consulta: 27/08/2020).

38 Véase M. WhiTE, Mapa de prácticas narrativas (Pranas Chile Ediciones, Santiago de Chile 2016).
} 
hijos en aras de un futuro que nunca llega- por medio de gestos mesiánicos de responsabilidad por el otro.

\section{(i) Memoria}

La (inter)subjetividad entonces es contada por personas y comunidades de sobrevivientes de los sistemas de exclusión como un tejido de re-membranza de lo des-membrado para reconstituir un cuerpo social herido. El trabajo de memoria es más que un mero trabajo de duelo, en el que prevalece aun la voluntad egoica como proyección del deseo subjetivo. Es más bien un tejido comunal de re-escritura a partir del pasado maldito, pero desde el corazón de las resistencias de quienes fueron ya aniquilados.

Las prácticas narrativas son, de esta manera, un camino de re-memoración recorrido por quienes han sido invisibilizados por los poderes establecidos, con frecuencia además re-victimizados por los poderes que manipular su duelo. Nombrar a los familiares desaparecidos, por ejemplo, conlleva una "contracción del tiempo" lineal de los verdugos con sus "verdades históricas" para dar paso a otra narración que visibiliza lo invisibilizado.

Y aun más, la memoria de quienes han sido aniquilados, re-construida por sus familiares en resistencia, es redimida del olvido y la injusticia como "promesa cumplida" que se realiza para algunos cuantos rescatados del olvido y, como primicia, apunta a la promesa de rescatar a todos los olvidados. En este sentido, una práctica inventada por los familiares de personas desaparecidas en México es realizar un ritual de "promesa cumplida" cuando logran identificar algunos restos humanos y son devueltos a sus familias. En ese acto simbólico y performativo se cumple la redención con toda su potencia escatológica, pues abre una grieta en el muro de la violencia para dar paso a otro modo de ser, como diría Emmanuel Levinas para hablar de la ética del Infinito. Pero, sobre todo, esos actos de los sobrevivientes son celebración de la vida que no cesa de clamar más vida para todas esas personas y comunidades.

(i) Esperanza

Como "centro vacío" de esa temporalidad mesiánica y kairológica insurge entonces la esperanza.

Bien decía Illich que la esperanza mesiánica nada tiene que ver con el futuro, invención prometeica que degeneró en la idea del progreso. Es más bien una potencia de experiencia propia de las subjetividades resilientes y en resistencia, que han hecho de su digna rabia un camino de dignidad, con justicia y -tal vez algún día- perdón y reconciliación.

La esperanza llega cuando se derriba el muro del odio y del resentimiento en la propia subjetividad, en el propio cuerpo, pero que no se cierra en la 
mismidad del dolor o del resentimiento, sino que se conecta con las heridas del cuerpo todo.

Esto posibilita la intersubjetividad como gracia de relación al otro que está marcada por la no reciprocidad violenta. Es el per-don en cuanto sobreabundancia del amor, no como debilidad sino como fortaleza de quienes han ido "al fondo de la noche" y vuelven para rescatar del absurdo a las víctimas y ofrecer un cambio de mundo a los verdugos, como Jesús en sábado santo, según la narrativa de la tumba vacía.

De este modo, las prácticas narrativas hacen emerger del fondo del dolor provocado por la ausencia de las personas desaparecidas un resplandor de dignidad con esperanza: "porque si encontramos a uno, seguiremos buscando a quienes nos faltan, hasta reunirnos de nuevo todas y todos". 